\title{
Evaluation of In-Ground Plastic-Hinge Length and Depth for Piles in Marine Oil Terminals
}

\author{
Rakesh K. Goel, ${ }^{\text {a) }}$ M.EERI
}

\begin{abstract}
This investigation evaluated the current recommendations for plastic-hinge length and depth for piles in marine oil terminals considering nonlinear pile and soil behavior, as well as two seismic design levels: Level 1 and Level 2. It was found that the plastic-hinge length depends on seismic design level, whereas depth is independent of seismic design level. For pre-stressed concrete piles, the current plastic-hinge length recommendations were generally found to be adequate for seismic design Level 2, but provided much smaller plastic-hinge length for Level 1. For hollow-steel piles, the current plastic-hinge length recommendation was generally found to be adequate for sands, but provided much smaller plastic-hinge length for clays for both seismic design levels. Furthermore, the current recommendations lead to much shallower plastic-hinge depth than that found in this investigation. [DOI: 10.1193/071813EQS207M]
\end{abstract}

\section{INTRODUCTION}

The Marine Oil Terminal Engineering and Maintenance Standards (MOTEMS) is the current standard used for the engineering analysis of marine oil terminals (MOTEMS 2010). MOTEMS describes the seismic analysis procedure for two performance levels and specifies earthquake motions to be used in the analysis. Level 1 has a 72-year return period and should cause no or minor damage with little to no interruption in service. Level 2, on the other hand, has a 475-year return period with controlled inelastic behavior and repairable damage, which may result in temporary closure of service that is restorable within months (MOTEMS 2010).

Seismic analysis in MOTEMS requires nonlinear static (or static pushover) analysis to determine the seismic displacement capacity of piles in marine oil terminals (MOTs). Displacement capacity of a pile is defined as the maximum displacement that can occur without exceeding material strain values (Goel and Saeedy 2012, Saeedy 2013, Goel 2013). Estimation of displacement capacity of the pile according to the MOTEMS procedure requires monitoring material strains during the pushover analysis.

For pushover analysis, the pile-soil system is typically modeled as a Winkler beam with discretized beam-column elements laterally supported below the mud line by soil springs (Goel 2013). Two different approaches are available for modeling nonlinear beam-column elements: distributed-plasticity and lumped-plasticity. In the distributed-plasticity approach, nonlinearity is permitted to spread over the element length and element moment-rotation

a) College of Engineering, California Polytechnic State University, San Luis Obispo, CA 93407-0350 
relationships are obtained by integrating section response. In the lumped-plasticity approach, nonlinearity is concentrated at the element ends in nonlinear flexural hinges and momentrotation relationships are obtained by calibrating the response of the lumped-plasticity element against the response of an "actual" frame element.

Since a lumped-plasticity model is implemented in most commercially available structural analysis software (e.g., SAP), practicing engineers prefer to use this approach. In this approach, the flexural hinge is modeled as a rigid perfectly plastic moment-rotation spring. The limiting value of the plastic rotation in the hinge at a selected design level is defined as:

$$
\theta_{P}=L_{P}\left(\phi_{L} \quad \phi_{y}\right)
$$

where $\theta_{P}=$ plastic rotation, $\phi_{L}=$ maximum pile-section curvature without exceeding MOTEMS-specified material strain limits, $\phi_{y}=$ yield curvature, and $L_{p}=$ calibrated plastichinge length.

The recommendation for plastic-hinge length, $L_{p}$, in Equation 1 was developed based on the simplifying assumption that the inelastic deformation in a cantilever member (Figure 1a) may be estimated by idealizing the actual height-wise distribution of curvature (dashed line in Figure 1c) with a distribution that includes superposition of a linear distribution with the maximum value equal to the yield curvature, $\phi_{y}$, at the cantilever base and a constant plastic curvature, $\phi_{P}$, over the plastic-hinge length, $L_{p}$, at the base (solid lines in Figure 1c; Priestley et al. 1996). The plastic-hinge length was calibrated so that the simplified curvature distribution gives the same plastic rotation and hence the same deflection as that in the actual structure. These underlying assumptions and simplification imply shorter plastic-hinge length for

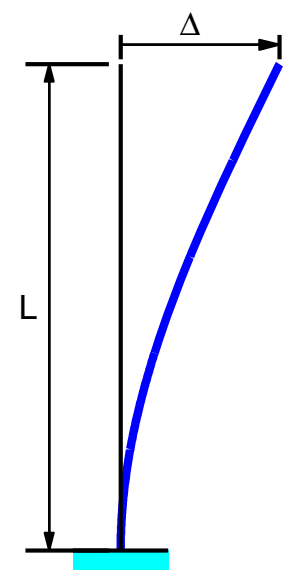

(a) Member

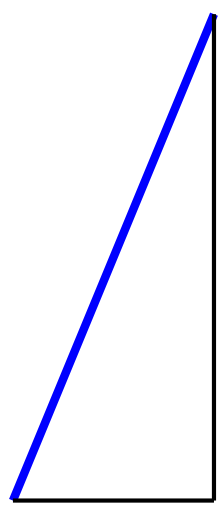

(b) BM

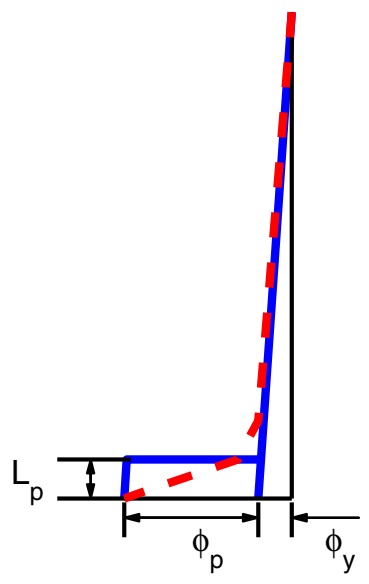

(c) Curvature

Figure 1. Inelastic deformation of a cantilever pile: (a) member deformation, (b) bending moment, and (c) actual curvature (dashed line) and idealized curvature (solid line). 
steeper slope and longer plastic-hinge length for milder slope of the curvature distribution in the plastic zone.

Clearly, the typical analytical procedures used in seismic evaluation of piles in MOTs require a prior knowledge of plastic-hinge length and plastic-hinge depth, in some cases. The MOTEMS-specified plastic-hinge length recommendations were adopted from those in Priestley et al. (1996), which were based on the work by Budek et al. (1994, 2000). These recommendations provide in-ground plastic-hinge length as a fraction of pile diameter for normalized stiffness and height parameters (Figure 2a). Although not specified in MOTEMS, Priestley et al. (1996) and Budek et al. (1994, 2000) also make recommendations for in-ground plastic-hinge depth (Figure $2 \mathrm{~b}$ ). The in-ground plastic-hinge depth recommendations are needed to ensure sufficient confinement in the plastic-hinge region to avoid premature failure. Plastic-hinge depth is also specified as a fraction of pile diameter for normalized stiffness and height parameters (Figure 2b).

The recommendations presented in Figure 2 were developed for a 6 - $\mathrm{ft} .(1.83 \mathrm{~m})$ diameter cast-in-drilled-hole (CIDH) reinforced concrete pile that is commonly used in bridges in California (Budek et al. 1994). Also, the recommendations were developed based on the assumptions that (1) limiting material strain is equal to ultimate failure strain in confined concrete, (2) soil is linear elastic, and (3) subgrade soil modulus increases linearly with depth below ground. However, piles used in MOTs are much smaller in cross sectional area than the 6-ft. (1.83 m) CIDH reinforced concrete pile used by Budek et al. (1994). For example, new wharf-type terminals in the Ports of Long Beach and Los Angeles use 24-in. $(0.61 \mathrm{~m})$ octagonal pre-stressed concrete piles. Also, the material strain limits in MOTEMS (Table 1) may differ significantly from those used by Budek et al. (1994). In particular, MOTEMS specify different concrete compression and tensile steel strains for the two design levels, which differ significantly from the ultimate failure strain in confined concrete used by Budek et al. (1994). Finally, the current engineering practice uses nonlinear soil properties with lateral force-deformation relationships specified though p-y curves

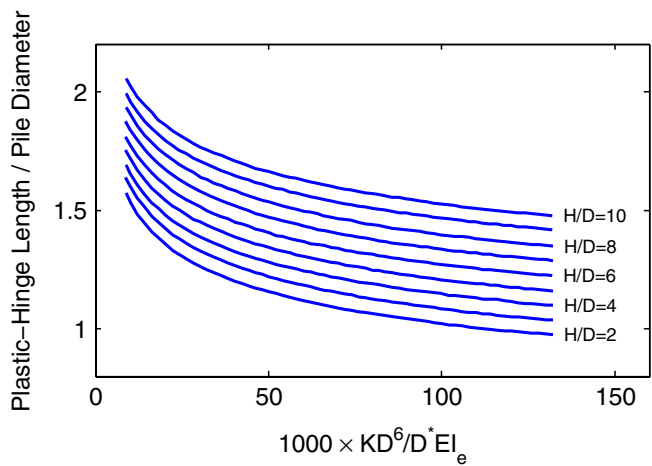

(a)

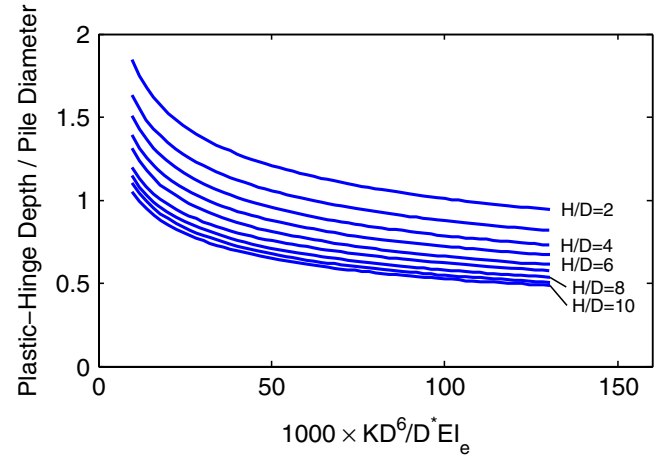

(b)

Figure 2. Current recommendations for (a) plastic-hinge length from MOTEMS Figure 31F-7-4 and (b) plastic-hinge depth from Priestley et al. (1996). 
Table 1. MOTEMS material strain limits

\begin{tabular}{lcc}
\hline \hline Component strain & Level 1 & Level 2 \\
\hline Maximum concrete compression strain pile-deck hinge & $\varepsilon_{c} \leq 0.004$ & $\varepsilon_{c} \leq 0.025$ \\
Maximum concrete compression strain in-ground hinge & $\varepsilon_{c} \leq 0.004$ & $\varepsilon_{c} \leq 0.008$ \\
Maximum reinforcing steel tension strain pile-deck hinge & $\varepsilon_{s} \leq 0.01$ & $\varepsilon_{s} \leq 0.05$ \\
Maximum reinforcing steel tension strain in-ground hinge & $\varepsilon_{s} \leq 0.01$ & $\varepsilon_{s} \leq 0.025$ \\
Maximum prestressing steel tension strain in-ground hinge & $\varepsilon_{p} \leq 0.005$ & $\varepsilon_{p} \leq 0.025$ \\
& (incremental) & (total) \\
\hline \hline
\end{tabular}

instead of a linearly increasing subgrade modulus with depth as assumed by Budek et al. (1994).

While wharf-type MOTs use the typical 24-in. octagonal concrete pile, steel pipe piles are also used on occasion. MOTEMS, however, does not provide recommendations for inground plastic-hinge length for steel piles. For steel piles, MOTEMS merely states, "The plastic-hinge length depends on the section shape and the slope of the moment diagram in the vicinity of the plastic-hinge" (MOTEMS 2010).

The recommendation for in-ground plastic-hinge length for steel piles is available in the Port of Long Beach (POLB) Wharf Design Criteria (Lai 2009). Instead of earthquake level 1 and level 2, POLB specifies operating level earthquake (OLE) and contingency level earthquake (CLE). An OLE is equivalent to MOTEMS Level 1 with the same 72-year return period and limited damage; a CLE is equivalent to MOTEMS Level 2 with the same 475-year return period and repairable damage. Thus, for all future references, OLE and CLE will be referred to as Level 1 and Level 2, respectively.

It is apparent from the discussion so far that there is a need to evaluate the plastic-hinge length and depth recommendation for typical piles and soil conditions that are used in MOTs. This study, therefore, recomputed the plastic-hinge length and depth for 24 -in. $(0.61 \mathrm{~m})$ octagonal pre-stressed concrete and hollow-steel pipe piles in six different soil conditions. The results of this study are used to evaluate the adequacy of current recommendations and suggest improvements, when needed.

\section{ANALYTICAL MODEL}

The nonlinear pile-soil system (Figure 3a) was modeled in OpenSees software developed at the Pacific Earthquake Engineering Research Center (McKenna and Fenves 2001). The pile was modeled using distributed-plasticity nonlinear beam-column elements (Figure $3 b$ ) with section properties defined by fiber sections. The pile below- and above-ground was discretized by elements of length equal to one-pile diameter. Since this discretization was adequate, finer discretization in the region of plastic hinging was not considered. The pre-stressed concrete pile section is defined using circular patch section with 100 subdivisions in both radial and circumferential directions for confined concrete core; circular patch with 5 subdivisions along the cover and 100 subdivisions in circumferential direction for unconfined concrete cover; and steel fibers at discrete locations of prestressing steel tendons. The concrete material is defined using Concrete01 material property 


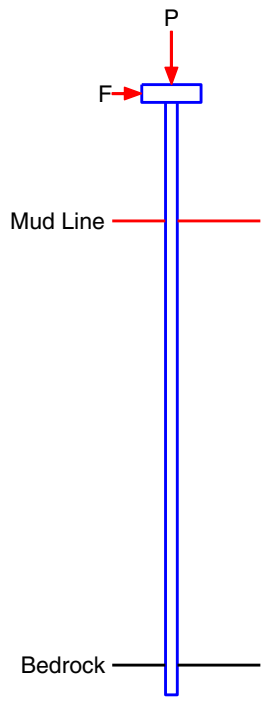

(a) Pile

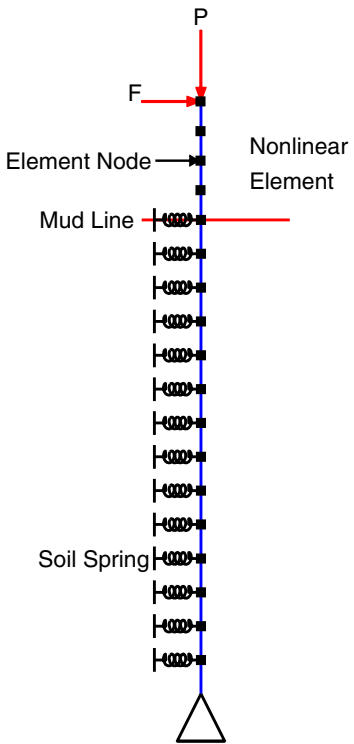

(b) Model

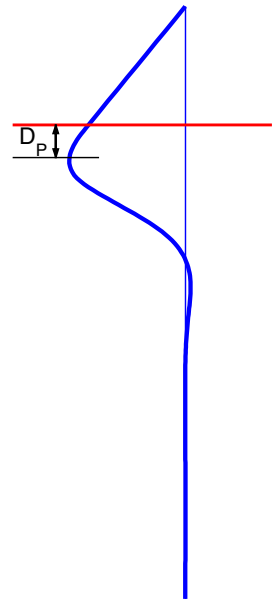

(c) Bending Moment

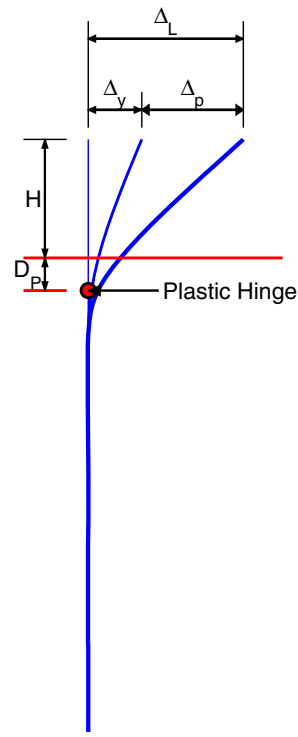

(d) Deflected Shape

Figure 3. Analytical approach for estimating plastic-hinge length and depth.

in OpenSees, which uses the Kent-Scott-Park stress-strain relationship model. The steel material is defined using ReinforcingSteel material property in OpenSees, which uses the Chang and Mander stress-strain relationship. The hollow-steel pile section is defined using circular patch section with 8 subdivisions along the wall thickness and 72 subdivisions along the circumferential direction, and ReinforcingSteel material property. The number of fibers in pile section was selected to balance accuracy in nonlinear section behavior and computational efficiency. Details of element types, fiber sections, and material properties are available in McKenna and Fenves (2001).

Since results from nonlinear studies may be sensitive to modeling assumptions such as the type of nonlinear element - force-based or displacement-based - and number of integration points (see Neuenhofer and Filippou 1997), additional sensitivity analysis was conducted to ensure that such assumptions do not influence the overall conclusions in this study. For this purpose, height-wise profiles of deflection, bending-moment, curvature, and pushover curve of the pile-soil system, plastic-hinge length, and plastic-hinge depth from analyses using displacement-based and force-based elements and two integration points per element were compared. This comparison indicated that the two types of elements lead to identical results. The results are not included here for the reason of brevity, but are available elsewhere (Goel 2013). Comparison of results from analyses using displacement-based nonlinear element with two and four integration points per element also indicated no difference. Therefore, the rest of this investigation used force-based nonlinear beam-column element with two integration points. 


\section{APPROACH TO ESTIMATE PLASTIC-HINGE LENGTH AND DEPTH}

A nonlinear static pushover analysis is conducted while monitoring material strains and element bending moments. The displacement capacity of the pile, $\Delta_{L}$, is defined as the maximum displacement at the top of the pile without exceeding selected material strain limits. The yield displacement, $\Delta_{y}$, is identified from the bilinear idealization of the pushover curve using an equal-area approach (Figure 4a). The bending moments are also monitored during analysis. The location of the plastic-hinge is assumed to occur at the location of the maximum bending moment below ground (Figure $3 \mathrm{c}$ and $3 \mathrm{~d}$ ). The soil-springs (Figure $3 \mathrm{~b}$ ) are modeled using bilinear p-y curves. The spring stiffness is defined as the p-value times the tributary pile length for the node where the spring is attached.

A moment-curvature analysis of the pile section is conducted while the material strains and curvature are monitored. The curvature, $\phi_{L}$, is defined as the maximum curvature without exceeding material strains. The yield curvature, $\phi_{y}$, is identified using a bilinear idealization of the moment-curvature relationship (Figure $4 b$ ).

The plastic-hinge length, $L_{p}$, is calculated from:

$$
L_{P}=\frac{\theta_{P}}{\phi_{L} \quad \phi_{y}}
$$

where $\phi_{L}=$ maximum curvature, $\phi_{y}=$ yield curvature, and $\theta_{P}$ is the plastic rotation computed from:

$$
\theta_{P}=\frac{\left(\begin{array}{ll}
\Delta_{L} & \Delta_{y}
\end{array}\right)}{\left(H+D_{P}\right)}
$$

in which $\Delta_{L}=$ displacement capacity, $\Delta_{y}=$ yield displacement, $H=$ height of the pile from ground level (or mud-line) to the aboveground point of contraflexure, and $D_{P}=$ plastic-hinge depth. This approach has been verified (Goel 2013) to be similar to that

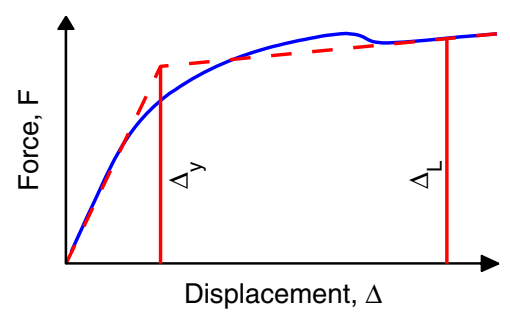

(a)

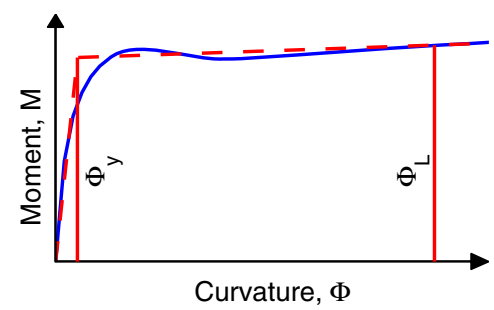

(b)

Figure 4. (a) Pushover curve and its bilinear idealization, and (b) moment-curvature curve and its bilinear idealization. 
used by Budek et al. (1994) in determining the plastic-hinge length and depth recommendations in Priestley et al. (1996).

\section{SOIL TYPES CONSIDERED}

Six soil types were considered in this investigation: dense sand, medium sand, loose sand, stiff clay, medium clay, and soft clay (Table 2). The soil was modeled as nonlinear p-y springs below the mud line at the nodes of each beam-column element (Figure 3b). Although hyperbolic p-y relationships are available (e.g., FHA 1986), structural analysis professions prefers to use simplified bilinear $p$-y curves. Therefore, bilinear $p$-y curves were developed by geotechnical engineers at Earth Mechanics, Inc. (EMI), using standard pile-soil interaction analysis for use in this investigation. The upper- and lower-bound multipliers are used to account for the simplification associated with bilinear idealization of $p$-y curve, uncertainty associated with soil properties, and the possibility of sloping ground conditions (Arulmoli and Martin 2009). For this investigation, the upper-bound and lower-bound p-y curves were obtained by multiplying the p-values by 1.5 and 0.67 , respectively, for all soil conditions. These multipliers were also provided by geotechnical engineers at EMI who have conducted many geotechnical studies for marine structures in California. The subgrade modulus values reported in Table 2 are taken from Table 31F-7-4 of MOTEMS. Additional details on soil properties and p-y curves are available in Goel (2013).

Table 2. Soil conditions considered and subgrade modulus (Table 31F-7-4 of MOTEMS)

\begin{tabular}{|c|c|c|c|c|c|}
\hline $\begin{array}{l}\text { MOTEMS } \\
\text { site class }\end{array}$ & $\begin{array}{c}\text { Shear } \\
\text { wave } \\
\text { velocity }\end{array}$ & $\begin{array}{c}\text { Standard } \\
\text { penetration } \\
\text { resistance }\end{array}$ & $\begin{array}{l}\text { Undrained } \\
\text { shear } \\
\text { strength }\end{array}$ & $\begin{array}{l}\text { Soil } \\
\text { type }\end{array}$ & $\begin{array}{l}\text { Subgrade } \\
\text { modulus, K }\end{array}$ \\
\hline \multicolumn{6}{|c|}{ Sand (API sand) } \\
\hline \multirow[t]{2}{*}{$\begin{array}{l}\text { D. Dense } \\
\text { soil }\end{array}$} & $\begin{array}{c}600 \quad 1,200 \mathrm{ft} / \mathrm{s} \\
183 \quad 366 \mathrm{~m} / \mathrm{s}\end{array}$ & 15 to 50 & & $\begin{array}{l}\text { Dense } \\
\text { sand }\end{array}$ & $\begin{array}{c}275 \mathrm{lb} / \mathrm{in}^{3} \\
74,644 \mathrm{kN} / \mathrm{m}^{3}\end{array}$ \\
\hline & & & & $\begin{array}{l}\text { Medium } \\
\text { sand }\end{array}$ & $\begin{array}{c}90 \mathrm{lb} / \mathrm{in}^{3} \\
24,429 \mathrm{kN} / \mathrm{m}^{3}\end{array}$ \\
\hline \multirow[t]{2}{*}{$\begin{array}{l}\text { E. Loose } \\
\text { soil }\end{array}$} & $\begin{array}{l}<600 \mathrm{ft} / \mathrm{s} \\
<183 \mathrm{~m} / \mathrm{s}\end{array}$ & $<15$ & & $\begin{array}{l}\text { Loose } \\
\text { sand }\end{array}$ & $\begin{array}{c}25 \mathrm{lb} / \mathrm{in}^{3} \\
6,786 \mathrm{kN} / \mathrm{m}^{3}\end{array}$ \\
\hline & & lay (Matlocl & & & \\
\hline $\begin{array}{l}\text { D. Dense } \\
\text { soil }\end{array}$ & $\begin{array}{cc}600 & 1,200 \mathrm{ft} / \mathrm{s} \\
183 & 366 \mathrm{~m} / \mathrm{s}\end{array}$ & & $\begin{array}{c}1,000 \\
2,000 \mathrm{lb} / \mathrm{ft}^{2} \\
48 \quad 96 \mathrm{kN} / \mathrm{m}^{2}\end{array}$ & Stiff clay & $\begin{array}{c}500 \mathrm{lb} / \mathrm{in}^{3} \\
13,5717 \mathrm{kN} / \mathrm{m}^{3}\end{array}$ \\
\hline \multirow[t]{2}{*}{$\begin{array}{l}\text { E. Loose } \\
\text { soil }\end{array}$} & $\begin{array}{l}<600 \mathrm{ft} / \mathrm{s} \\
<183 \mathrm{~m} / \mathrm{s}\end{array}$ & & $\begin{array}{l}<1,000 \mathrm{lb} / \mathrm{ft}^{2} \\
<48 \mathrm{kN} / \mathrm{m}^{2}\end{array}$ & $\begin{array}{l}\text { Medium } \\
\text { clay }\end{array}$ & $\begin{array}{c}100 \mathrm{lb} / \mathrm{in}^{3} \\
27,143 \mathrm{kN} / \mathrm{m}^{3}\end{array}$ \\
\hline & & & & Soft clay & $\begin{array}{c}20 \mathrm{lb} / \mathrm{in}^{3} \\
5,429 \mathrm{kN} / \mathrm{m}^{3}\end{array}$ \\
\hline
\end{tabular}




\section{PRE-STRESSED CONCRETE PILES}

The plastic-hinge length and depth recommendations in this study are developed for a 24-in. $(0.61 \mathrm{~m})$ octagonal pre-stressed concrete pile (Figure 5a) used in typical wharf-type MOTs. The selected material properties of the pile are: unconfined concrete compressive strength $f_{c}^{\prime}=6.5 \mathrm{ksi}(44.8 \mathrm{MPa})$ and pre-stressing steel tendon yield strength, $f_{y}=270 \mathrm{ksi}(1860 \mathrm{MPa})$. The pile section consists of 16 pre-stressing tendons, each with area of 0.217 in. $^{2}\left(140 \mathrm{~mm}^{2}\right)$, \#11 wire spiral pitched at $2.5 \mathrm{in}$. $(63.5 \mathrm{~mm})$, and 3 in. $(76.2 \mathrm{~mm})$ cover. The steel tendons are pre-stressed to $70 \%$ of their yield stress. The pile supports an axial load equal to $5 \%$ of its axial load capacity. The pile is considered to be free to deflect horizontally and free to rotate at its top. The pile depth below ground level (or mud line) is fixed at $80 \mathrm{ft}$. $(24.4 \mathrm{~m})$. The pile height above ground level is varied between $20 \mathrm{ft} .(6.1 \mathrm{~m})$ and $4 \mathrm{ft}$. $(1.22 \mathrm{~m})$, which correspond to pile height to pile diameter ratio, $H / D$, between 10 and 2. The pile section moment-curvature relationship is shown in Figure 5b.

Figure 6 presents length and depth of the in-ground plastic-hinge for the selected pile, six soil types, and two MOTEMS seismic design levels. Figure 6a also includes the in-ground plastic-hinge lengths estimated from current MOTEMS recommendations (Figure 2a) as well as from POLB. Figure 6b includes the plastic-hinge depth from Priestley et al. (1996; Figure $2 b$ ). These results lead to the following important observations.

The plastic-hinge length differs for two MOTEMS seismic design levels (Figure 6a). In particular, the plastic-hinge length for Level 1 is longer than that for Level 2. This trend is applicable for all soil types and pile $H / D$ values. However, the difference between plastichinge length for Level 1 and 2 tends to be larger for softer soils, such as loose sand and soft clay compared to stiffer soils such as dense sand and stiff clay.

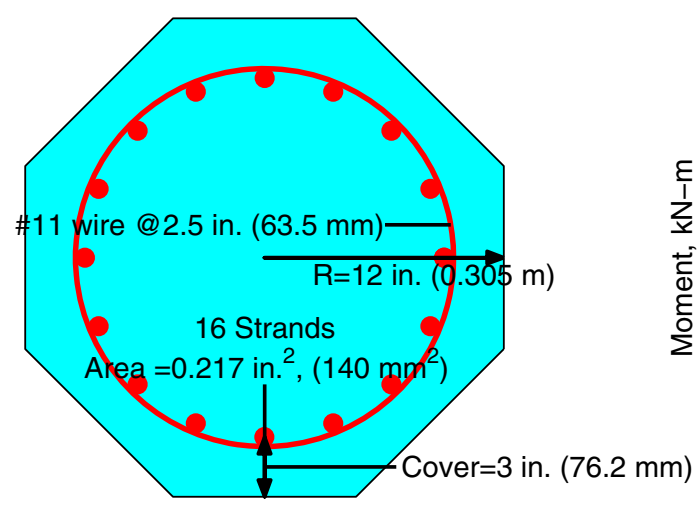

(a)

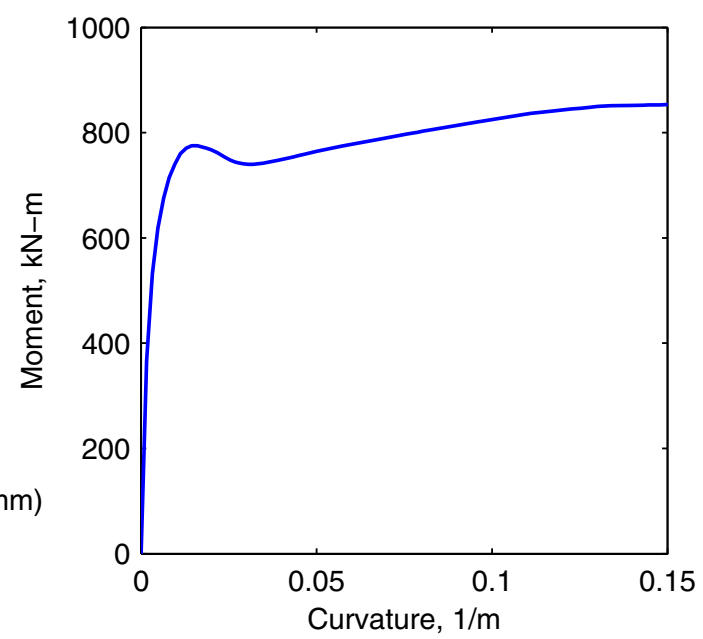

(b)

Figure 5. Pre-stressed reinforced-concrete pile considered: (a) Pile section and (b) momentcurvature relationship. 

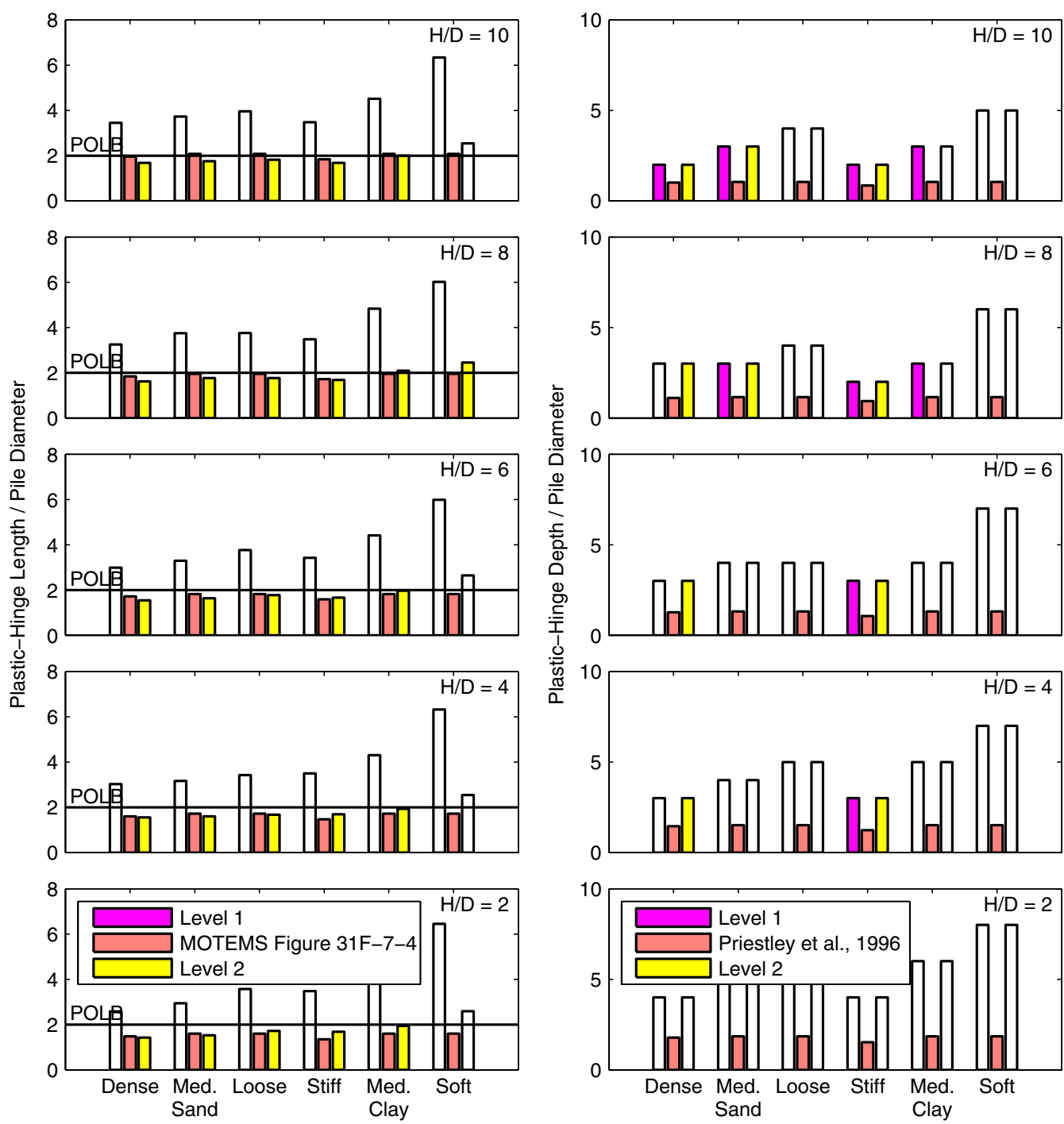

(a)

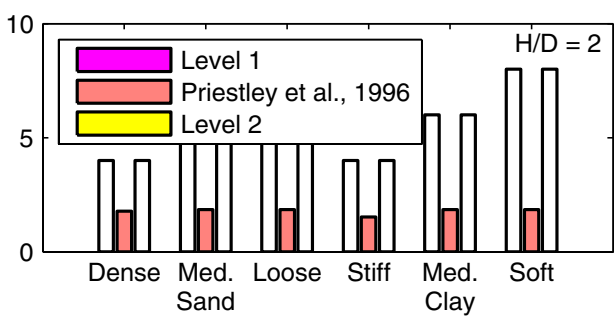

(b)

Figure 6. In-ground plastic-hinge (a) length and (b) depth for pre-stressed concrete piles in MOTs.

To understand the reasons for different plastic-hinge length for the two seismic design level, Figure 7 compares the height-wise distribution of normalized curvature in pre-stressed concrete piles for six soil types and $H / D=10$. It is useful to recall that the plastic-hinge length will be shorter for steeper slope and longer for milder slope of the curvature distribution in the plastic zone (see Figure 1). The results presented in Figure 7 clearly show that the slope of the curvature distribution in the plastic-hinge zone is milder for Level 1 compared to Level 2 for all soil types, which explains the observation in Figure 6 of a longer plastic-hinge 

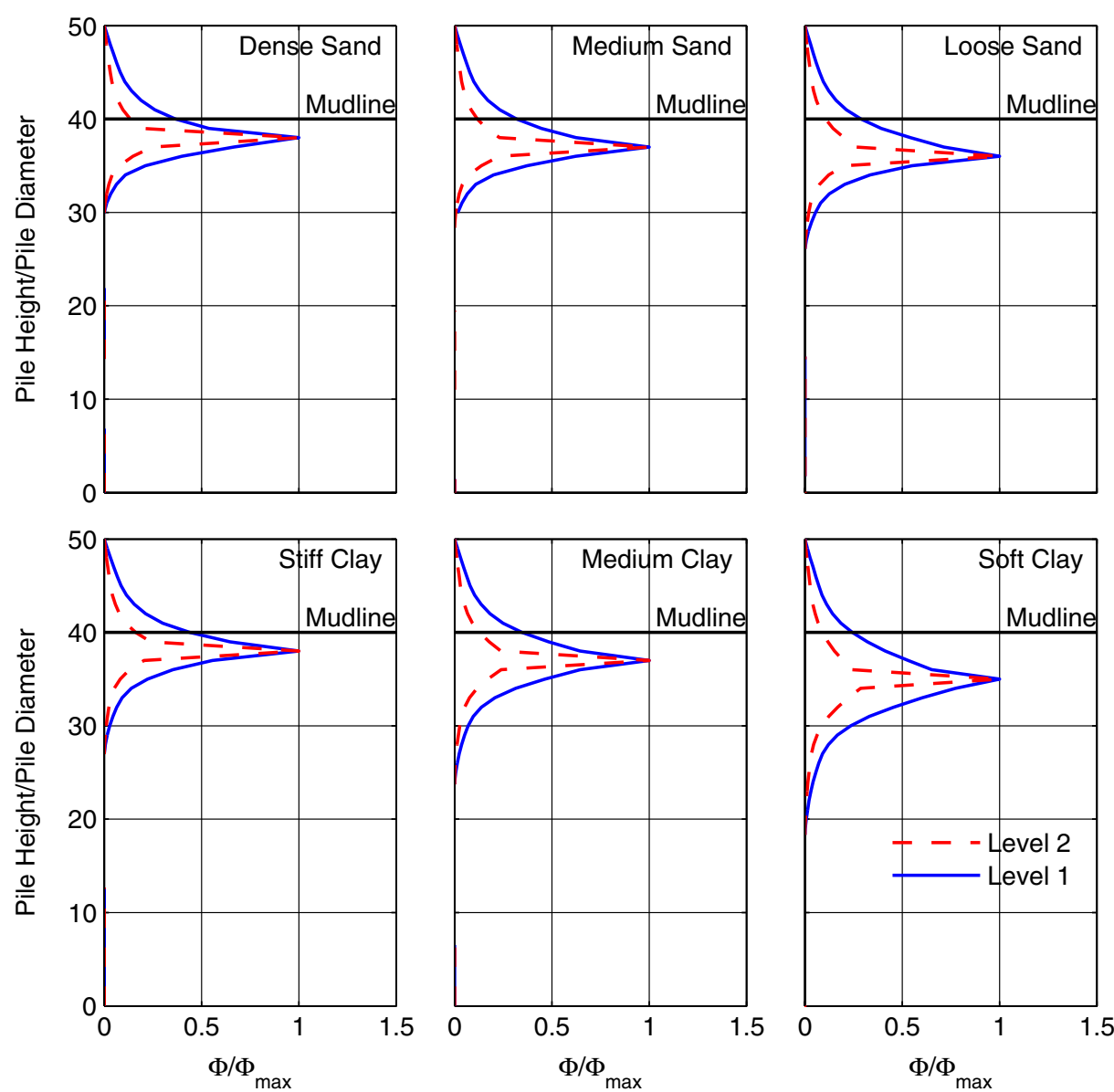

Figure 7. Height-wise distribution of normalized curvature in pre-stressed concrete piles with $H / D=10$ for six soil types and seismic design levels 1 and 2.

length for Level 1 compared to Level 2. Furthermore, results in Figure 7 show that the difference in the slope of the curvature distribution in the plastic-hinge zone is much larger for softer soils, such as loose sand and soft clay, compared to stiffer soils, such as dense sand and stiff clay, which explains a much larger difference in the plastic-hinge length between the two seismic design level for softer soil types compared to stiffer soil types observed in Figure 6.

The MOTEMS recommended plastic-hinge length appears to be adequate for the Level 2 design for most soil types, except for soft clay, as apparent from very similar values from the results obtained in this study and from the MOTEMS recommendation (Figure 6). The slightly shorter values of the plastic-hinge length from the MOTEMS recommendation for soft clays is due to extrapolation assumptions used in estimating the plastic-hinge length from Figure 2a for MOTEMS. In particular, the value of $1,000 K D^{6} / D E I_{e}$ for the selected pile is lower than the first data point available at $1,000 K D^{6} / D E I_{e}=6$ for curves in Figure 2a. In this 
investigation, the plastic-hinge length was capped at the value at 1,000 $K D^{6} / D E I_{e}=6$ if the 1,000 $K D^{6} / D E I_{e}$ value for the selected pile was lower. However, the trend in Figure 2a indicates a longer plastic-hinge length for lower values of 1,000 $K D^{6} / D E I_{e}$, which in turn indicates that the values of the plastic-hinge length from MOTEMS may end up being similar to that from the current study if additional data were available in Figure 2a.

The Port of Long Beach (POLB) recommends plastic-hinge length equal to two times the pile diameter regardless of the soil type or $H / D$ value. The results presented in Figure $6 a$ indicate that the POLB recommendation is reasonably close to the values from MOTEMS as well as from the current investigation for Level 2 seismic design for all soil types for $H / D=$ 10 and 8, and for medium and soft clays for remaining values of $H / D$. For other cases, the POLB recommendation leads to slightly longer plastic-hinge length. Since longer plastichinge length leads to larger pile displacement, the POLB recommendation may lead to un-conservatively larger seismic displacement capacity for Level 2 seismic design for a few soil types and $H / D$ values.

MOTEMS as well as POLB recommended plastic-hinge lengths for Level 1 are much smaller than the values found in this investigation. Since shorter plastic-hinge length lead to smaller displacement capacity, it appears that current the MOTEMS and POLB in-ground plastic-hinge length recommendations will lead to overly conservative lower pile displacement capacity for seismic design Level 1 for all soil types and $H / D$ values.

It is also useful to point out that the current MOTEMS recommendations for plastic-hinge length (Priestley et al. 1996; Budek et al. 1994, 2000) were computed at failure compression strain in the confined concrete. Clearly, such material strain levels are appropriate for MOTEMS Level 2 but not for MOTEMS Level 1 for which the material strains are much lower (Table 1). Therefore, it is not surprising that the plastic-hinge length for Level 1 found in this investigation differs significantly from the current MOTEMS recommendations.

It is useful to emphasize that MOTEMS, POLB, or general engineering practice make no distinction in plastic-hinge length for the two different seismic design levels, i.e., a single value of plastic-hinge length is used in estimating displacement capacity of piles for both seismic design levels. Therefore, results presented in Figure 6 highlight an important short-coming of current practice: using the same plastic-hinge length for both seismic design levels leads to an overly conservative and lower displacement capacity estimate for Level 1. Therefore, it is preferable that two separate analyses be conducted using different values of plastic-hinge lengths for the two seismic design levels to more realistically estimate the displacement capacity at both design levels.

Figure $6 \mathrm{~b}$ presents depth of in-ground plastic-hinges for two MOTEMS seismic design levels along with the current value recommended by Priestley et al. (1996). It is apparent that the current recommendation leads to a depth of plastic-hinge that is much shallower than that determined in this investigation. While the current recommendation provides a plastic-hinge depth below ground of approximately 1D for selected pile type, this study indicates depth varying from $2 \mathrm{D}$ to $7 \mathrm{D}$ depending on the soil type. Unlike plastic-hinge length, the depth of plastic-hinge below ground is independent of the MOTEMS seismic design level.

As mentioned previously, the engineering practice uses upper- and lower-bound estimates of soil properties in addition to the nominal values to bound response estimates 
for possible variations in the soil characteristics. The preceding discussion clearly indicates that plastic-hinge length and depth depend on soil properties. Since lower- and upper-bound soil characterization affects the initial stiffness of the soil springs, this study examined how the plastic-hinge length and depth is affected by the lower- and upper-bound properties. For this purpose, the plastic-hinge length and depth are compared in Figures 8 and 9 for lowerbound, nominal, and upper-bound soil properties for Level 1 and Level 2, respectively.
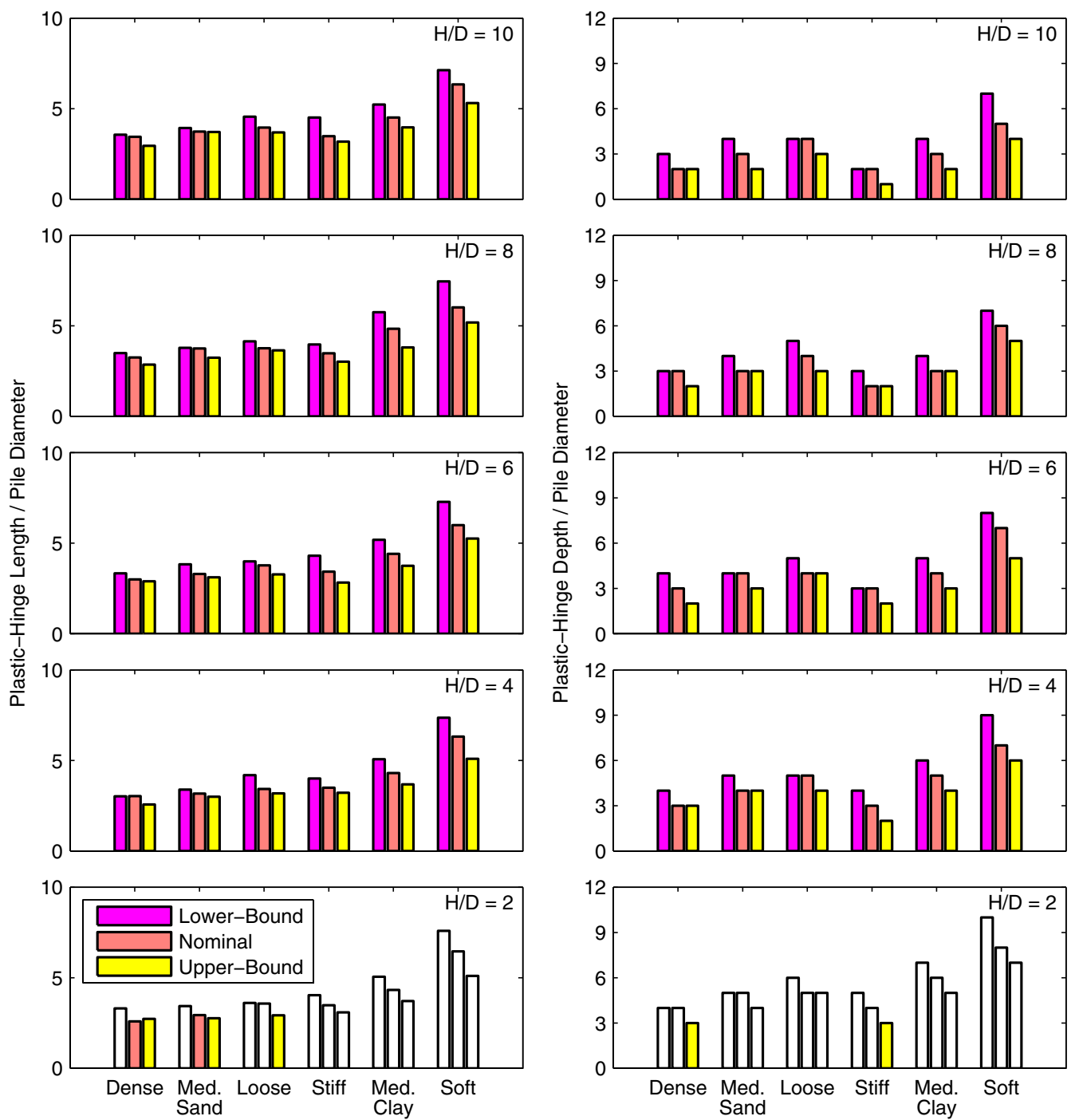

(a)

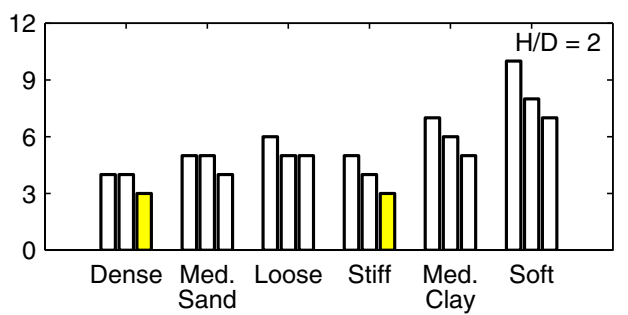

(b)

Figure 8. Level 1 in-ground plastic-hinge (a) length and (b) depth of pre-stressed concrete piles in MOTs for lower-bound, nominal, and upper-bound soil properties. 

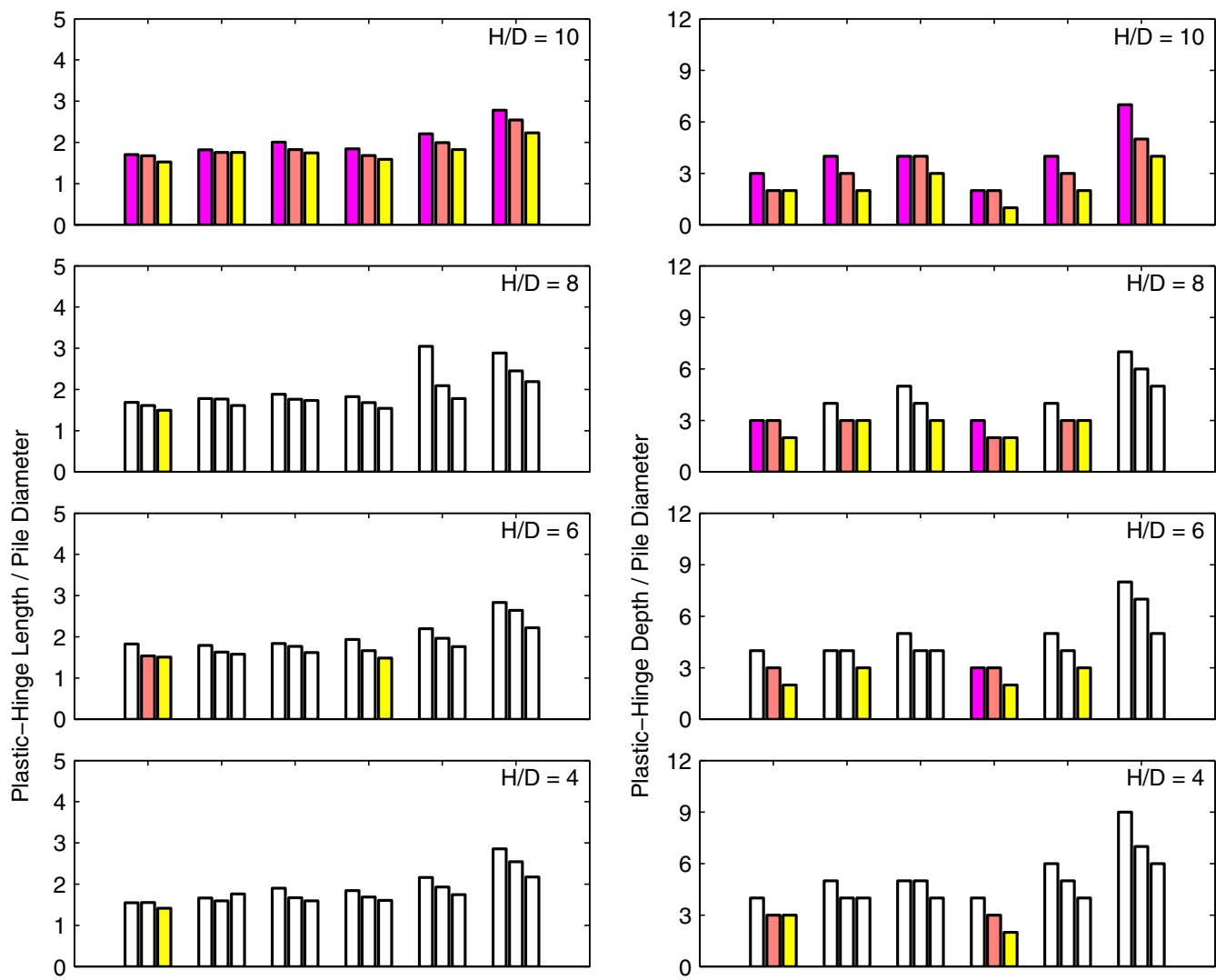

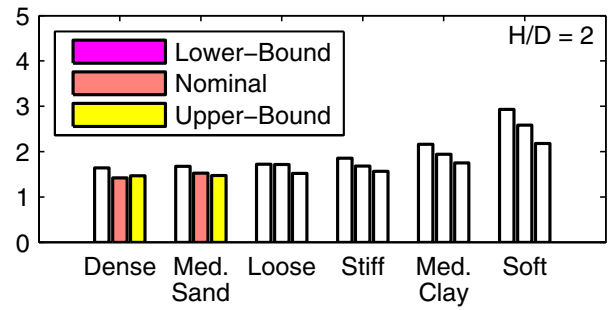

(a)

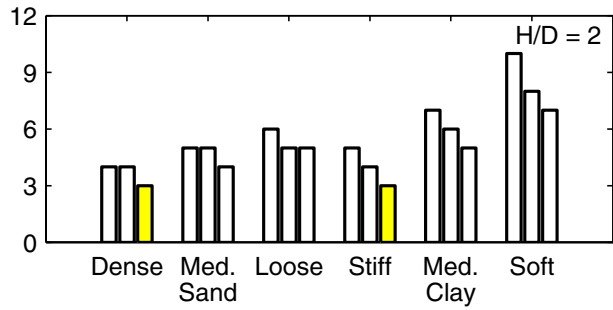

(b)

Figure 9. Level 2 in-ground plastic-hinge (a) length and (b) depth of pre-stressed concrete piles in MOTs for lower-bound, nominal, and upper-bound soil properties.

The results presented in Figures 8a and 9a show that the plastic-hinge length is essentially unaffected by the lower- and upper-bound soil properties for the three types of sands considered in this investigation. For clays, however, the plastic-hinge length tends to be longer for lower-bound and shorter for upper-bound soil properties compared to the nominal soil value. The plastic-hinge depth, in general, is lower for upper-bound and deeper for 
lower-bound soil properties (Figure $8 \mathrm{~b}$ and $9 \mathrm{~b}$ ). This is expected because softer soil permits deeper migration of plastic-hinge location.

\section{HOLLOW-STEEL PILES}

Reported in this section are the results for hollow-steel pile with 24 in. $(0.61 \mathrm{~m})$ diameter and $0.5 \mathrm{in} .(12.7 \mathrm{~mm})$ wall thickness. Additional results for hollow-steel piles with $36 \mathrm{in}$. $(0.91 \mathrm{~m})$ diameter and $0.75 \mathrm{in} .(19 \mathrm{~mm})$ wall thickness, and 48 in. $(1.22 \mathrm{~m})$ diameter and $1 \mathrm{in}$. $(25.4 \mathrm{~mm})$ wall thickness are available in Goel (2013). The yield strength of the steel was $50 \mathrm{ksi}(345 \mathrm{MPa})$. The pile configuration and modeling is similar to that described previously for pre-stressed concrete pile.

Figure 10 presents lengths and depths of in-ground plastic-hinges in the selected hollowsteel pile, respectively, for six soil types, and two MOTEMS seismic design levels. Also included in Figure 10a is the in-ground plastic-hinge length from current POLB recommendations. These results lead to the following important observations.

As noted previously for pre-stressed concrete piles, the plastic-hinge length differs for the two MOTEMS seismic design levels (Figure 10a). This trend is applicable for all soil types and pile $H / D$ values. However, the difference between plastic-hinge length for Level 1 and 2 tends to be larger for softer soils such as loose sand and soft clay compared to stiffer soils such as dense sand and stiff clay.

The plastic-hinge length for Level 2 tends to be larger than for Level 1 seismic design (Figure 10a). This trend is opposite to that observed previously for pre-stressed concrete piles for which plastic-hinge length was found to be smaller for Level 2 compared to Level 1 seismic design (Figure 6a).

To understand reasons for these differences Figure 11 presents the height-wise distribution of normalized curvatures for the selected hollow-steel piles for six soil types and $H / D=10$. Once again, it is useful to recall that the plastic-hinge length will be shorter for steeper slope and longer for milder slope of the curvature distribution in the plastic zone (see Figure 1). The results presented in Figure 11 clearly show that the slope of the curvature distribution in the plastic-hinge zone is much milder for Level 2 compared to Level 1 for all soil types, which explains the observation in Figure 10a of longer plastichinge length for Level 2 compared to Level 1. The opposite trend was visible for pre-stressed concrete piles (Figure 7), where the slope of the curvature distribution in the plastic-hinge zone was much milder for Level 1 compared to Level 2 for all soil types.

The milder slope of the curvature distribution in the plastic-hinge zone for hollow-steel pile for the Level 2 design may be attributed to the more ductile nature of steel, which permits gradual spread of the curvature over height with increasing pile displacement. For prestressed concrete piles, however, the curvature tends to concentrate over a very short length after initiation of concrete crushing that is expected for pile displacements associated with seismic design Level 2.

Results in Figure 10a also indicate that the plastic-hinge length for both design levels tends to be longer for softer soils such as loose sand and soft clay compared to stiffer soils such as dense sand and stiff clay. This is due to the slope of the curvature distribution in the 

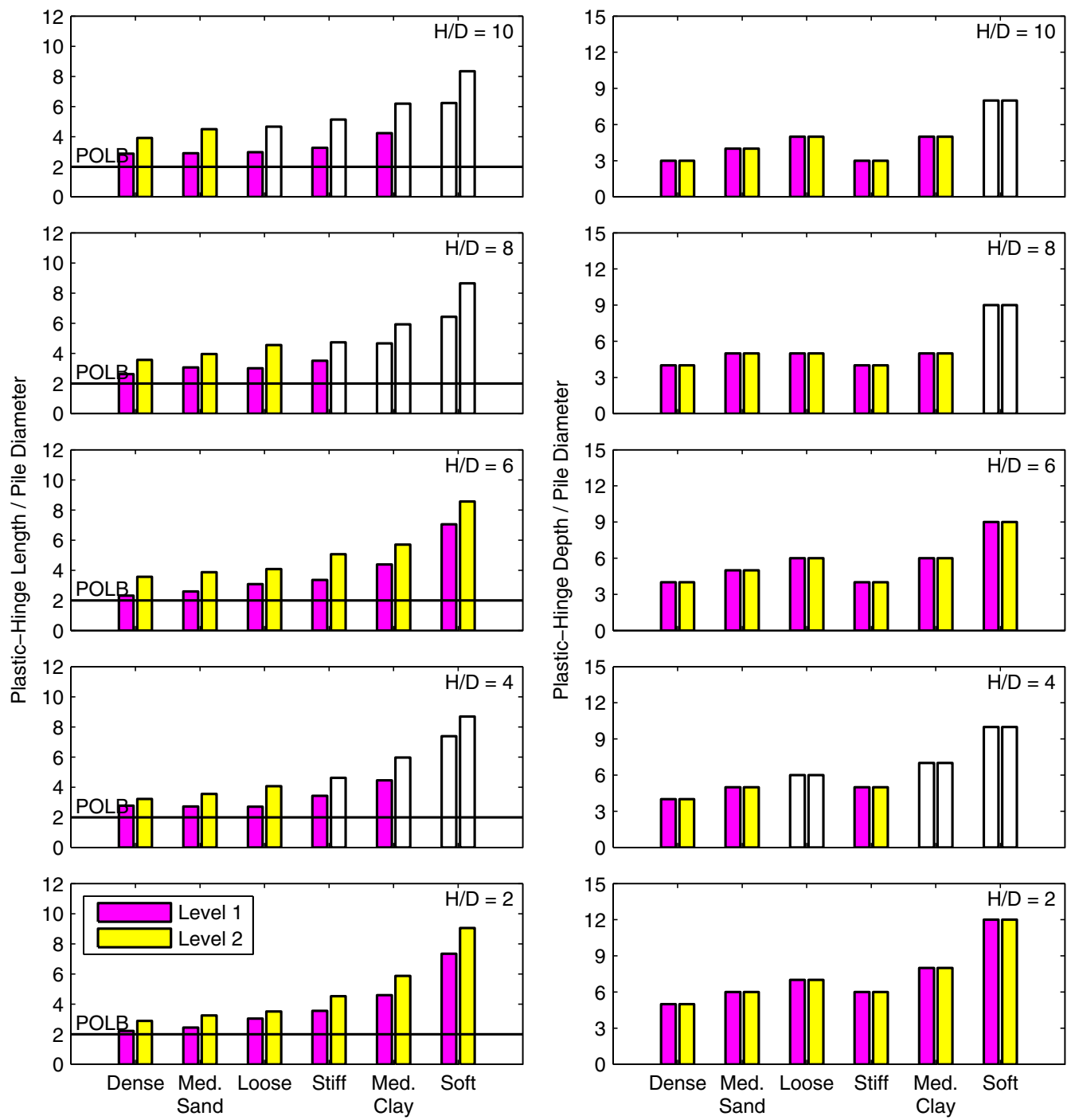

(a)

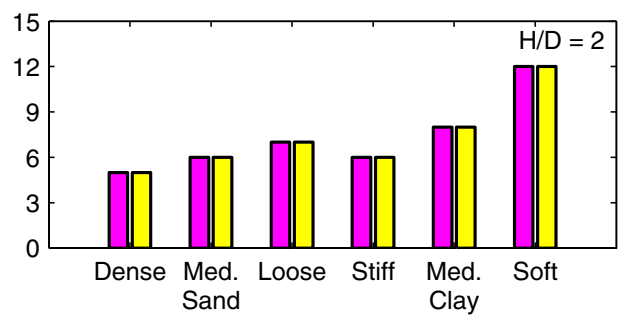

(b)

Figure 10. In-ground plastic-hinge (a) length and (b) depth for hollow-steel piles in MOTs.

plastic-hinge zone being much milder for softer soils such as loose sand and soft clay compared to stiffer soils such as dense sand and stiff clay as apparent from results in Figure 11.

POLB recommends plastic-hinge length equal to two times the pile diameter regardless of the soil type or $H / D$ value. The results presented in Figure 10a, indicate that the POLB recommendation leads to generally adequate plastic hinge length for sands but much shorter plastic-hinge length for clays. This indicates that the POLB recommendation may lead to overly conservative smaller seismic displacement capacity for hollow-steel piles in clays. 

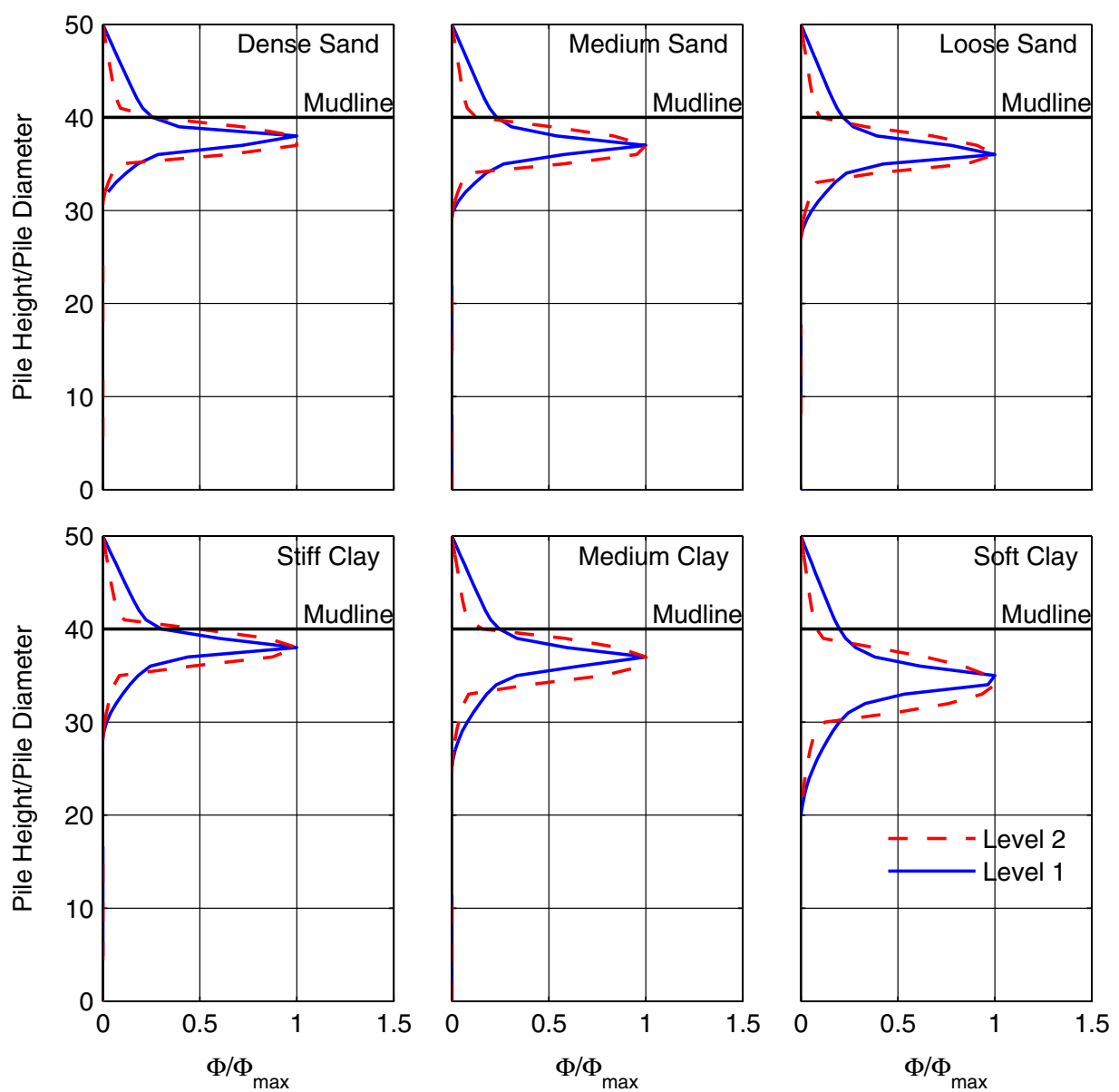

Figure 11. Height-wise distribution of normalized curvature in hollow-steel piles with $H / D=$ 10 for six soil types and seismic design levels 1 and 2 .

As noted previously for pre-stressed concrete piles, the results for hollow-steel piles also highlight the need for two separate analyses using different values of plastic-hinge lengths for the two seismic design levels.

Figure 10b presents depth of in-ground plastic-hinges for two MOTEMS seismic design levels. These results indicate that the depth of the in-ground plastic-hinge varies from $3 \mathrm{D}$ to 12D depending on the soil type. Unlike plastic-hinge length, the depth of the plastic-hinge below ground is independent of the MOTEMS seismic design level.

Although results are not presented here, a comparison for three different piles diameters indicates that results - plastic-hinge length and depth — are very similar for all three diameters (Goel 2013). This indicates that the normalized plastic-hinge length and depth values may be considered to be independent of the pile diameter. 
As mentioned previously, the engineering practice uses upper- and lower-bound estimates of soil properties, in addition to the nominal values, to bound response estimates for possible variations in the soil characteristics. Similar to results presented previously for pre-stressed concrete pile, Figures 12 to 13 present results for the selected hollowsteel pile and lower-bound, nominal, and upper-bound soil properties for Level 1 and Level 2.
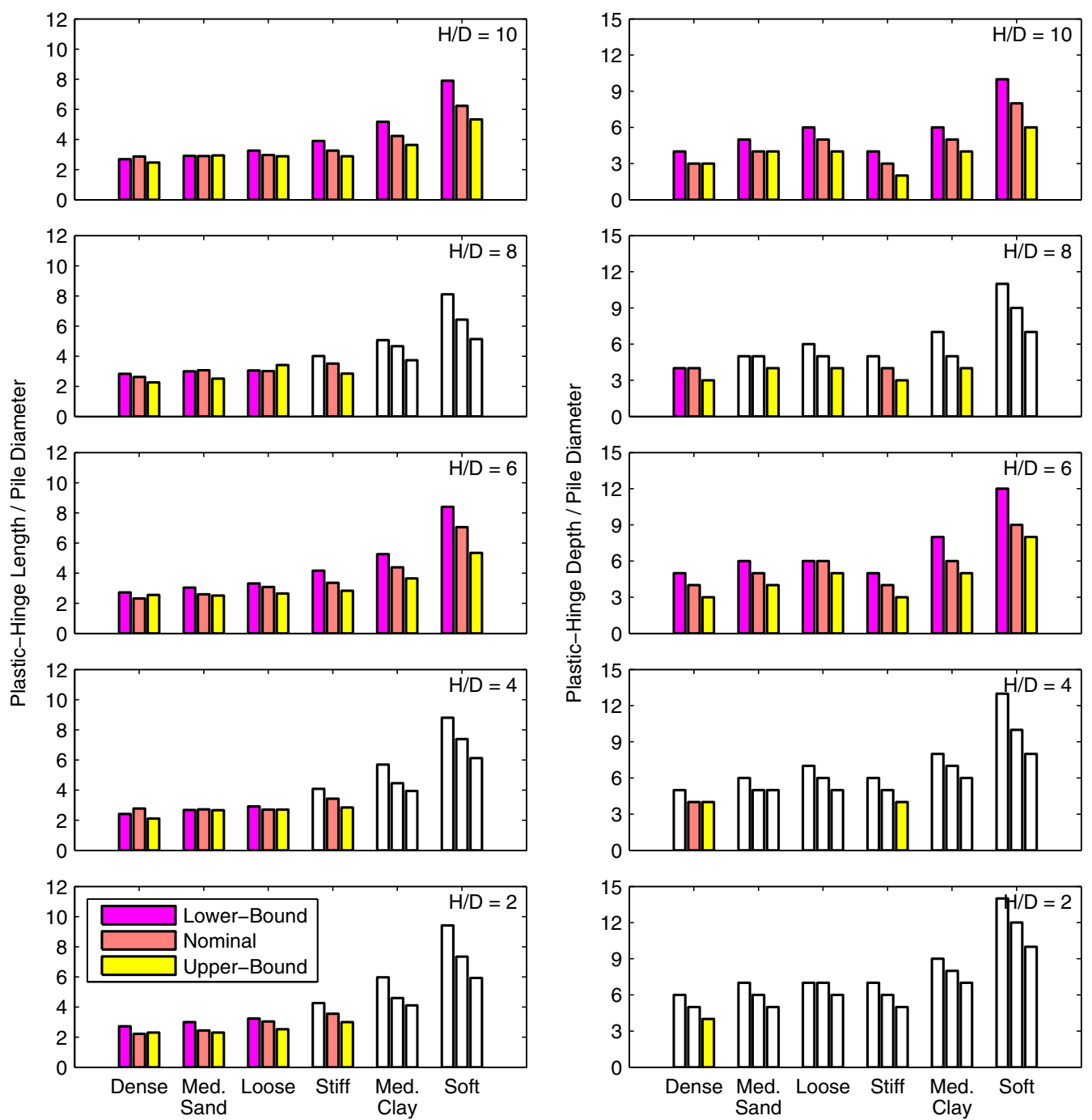

(a)

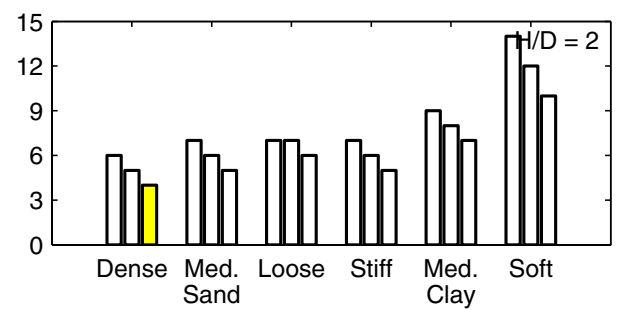

(b)

Figure 12. Level 1 in-ground plastic-hinge (a) length and (b) depth of 24-in $(0.61 \mathrm{~m})$ hollowsteel piles in MOTs for lower-bound, nominal, and upper-bound soil properties. 

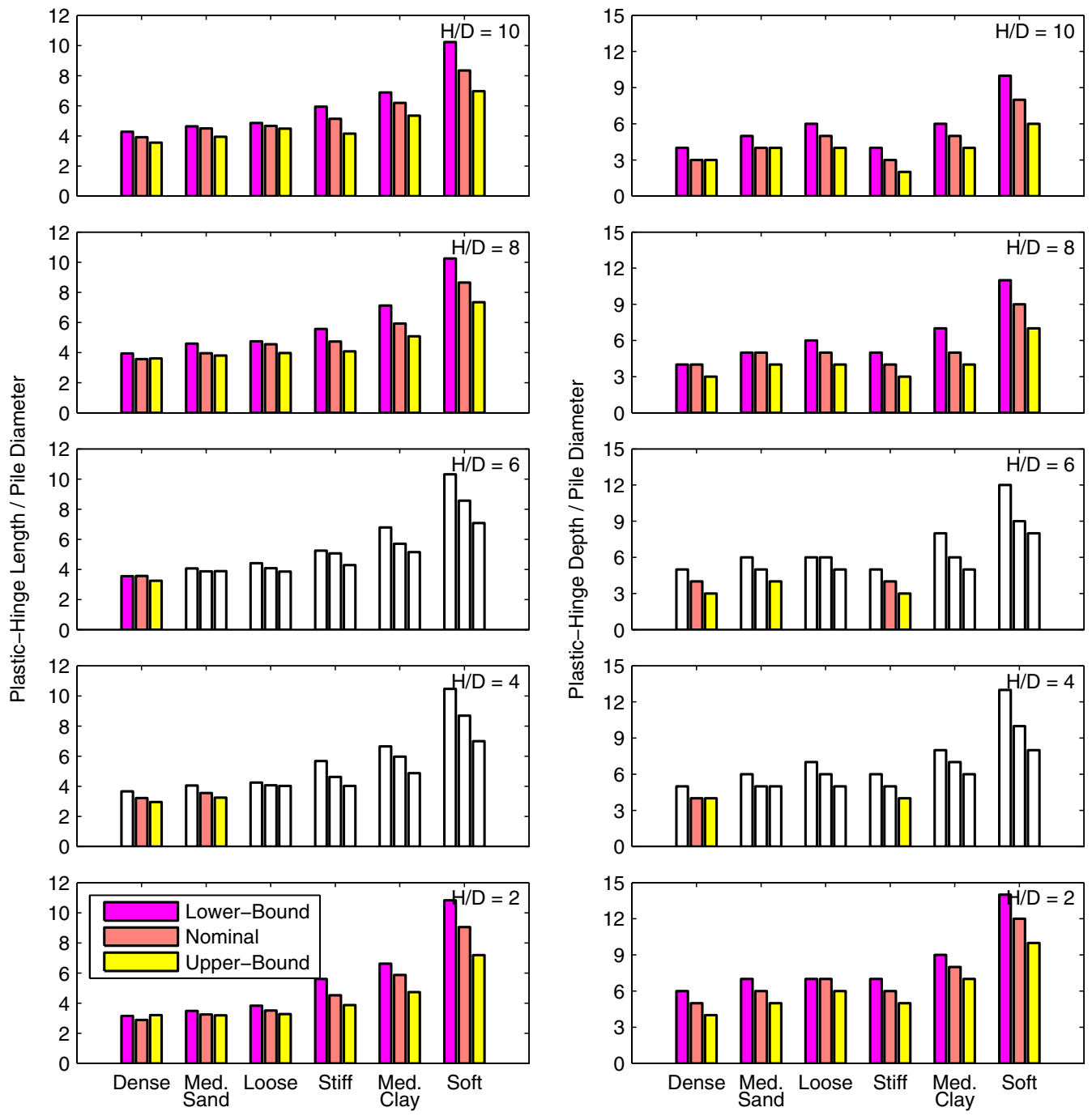

(a)

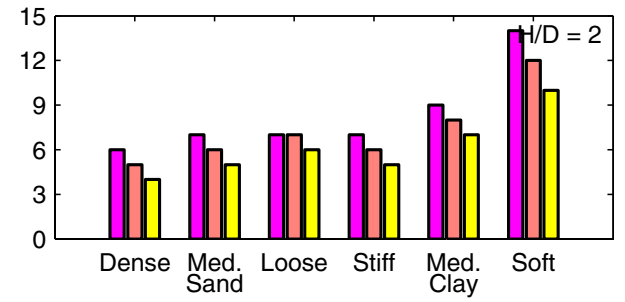

(b)

Figure 13. Level 2 in-ground plastic-hinge (a) length and (b) depth of 24-inch $(0.61 \mathrm{~m})$ hollowsteel piles in Marine Oil Terminals for lower-bound, nominal, and upper-bound soil properties.

As noted previously for pre-stressed concrete piles, the results presented in Figure 12a and 13a show that the plastic-hinge length is essentially unaffected by the lower- and upperbound soil properties for the three types of sands considered in this investigation. For clays, however, the plastic-hinge length tends to be longer for lower-bound and shorter for upperbound soil properties compared to the nominal soil value. The explanation for this observation is the same as that for pre-stressed concrete piles. The plastic-hinge depth, in general, is 
lower for upper-bound and deeper for lower-bound soil properties (Figures 12b and 13b). This is expected because location of the plastic-hinge is deeper for softer soils.

\section{CONCLUSIONS AND RECOMMENDATIONS}

This investigation examined the current recommendations for plastic-hinge length and depth for piles and soil properties typical of those in MOTs. For this purpose, 24-in. (0.61 m) octagonal pre-stressed concrete and hollow-steel piles supported in six different soil typesdense sand, medium sand, loose sand, stiff clay, medium clay, and soft clays-were analyzed. Nonlinear behaviors for both pile and soil was considered and MOTEMS-specified strain levels were used. A comparison of results with current recommendations in MOTEMS and POLB, when appropriate, led to the following conclusions:

The plastic-hinge length differs for two MOTEMS seismic design levels. The plastichinge length was found to be longer for Level 1 compared to Level 2 for pre-stressed concrete piles, and longer for Level 2 compared to Level 1 for hollow-steel piles.

The trends in plastic-hinge length for the two seismic design levels were found to be related to the slope of the curvature distribution in the plastic-hinge region: a milder slope led to longer plastic-hinge length and vice versa. It was found that the slope of the curvature distribution became steeper for Level 2 compared to Level 1 after crushing of the concrete in pre-stressed concrete piles due to brittle material behavior, whereas it became milder for Level 2 compared to Level 1 for hollow-steel piles due to ductile material behavior.

For pre-stressed concrete piles and seismic design Level 2, the MOTEMS-recommended plastic-hinge length is generally adequate, whereas the POLB-recommended value is adequate for all soil types for $H / D=10$ and 8 , and for medium and soft clays for $H / D=6,4$, and 2. For remaining cases, the POLB recommendation leads to a slightly longer plastichinge length, which may lead to un-conservatively larger seismic displacement capacity. The MOTEMS and the POLB recommended plastic-hinge lengths for Level 1 are much smaller than the values found in this investigation. Therefore, current MOTEMS and POLB in-ground plastic-hinge length recommendations result in overly conservative lower pile displacement capacity for seismic design Level 1 . The current recommendation result in a depth of plastic-hinge that is much shallower than that found in this investigation. While the current recommendation leads to a depth of plastic-hinge below ground to be approximately $1 \mathrm{D}$, this study found depths to vary from 2D to 7D depending on the soil type. Furthermore, the depth of the plastic-hinge below ground is independent of the MOTEMS seismic design level.

For hollow-steel piles, the POLB recommendation in most cases leads to adequate plastic-hinge length for sand and much shorter plastic-hinge length for clays, implying that the POLB recommendation may result in an overly conservative smaller seismic displacement capacity of piles in clay. The depth of the in-ground plastic-hinge varies from $3 \mathrm{D}$ to $12 \mathrm{D}$ depending on the soil type. Similar to pre-stressed concrete piles, depth of the plastichinge below ground is independent of the MOTEMS seismic design level. Furthermore, normalized plastic-hinge length and depth values do not depend on the pile diameter. 
General engineering practice uses a single value of plastic-hinge length in estimating displacement capacity of piles for both seismic design levels. Based on results of this investigation, it is recommended that that two separate analyses be conducted using different plastic-hinge lengths for the two seismic design levels to more realistically estimate the displacement capacity at both design levels.

The plastic-hinge length is essentially unaffected by the lower- and upper-bound soil properties for the three types of sands considered in this investigation. For clays, however, the plastic-hinge length tends to be longer for lower-bound and shorter for upper-bound soil properties compared to the nominal soil value. The plastic-hinge depth, in general, is shallower for upper-bound and deeper for lower-bound soil properties because the plastic-hinge tends to migrate deeper for softer soils.

\section{ACKNOWLEDGMENTS}

This research investigation is supported by the California State Lands Commission (CSLC) under Contract No. C2009-044; this support is gratefully acknowledged. The author would especially like to thank Avinash Nafday and Martin Eskijian, who were the CSLC Project Managers for this contract, and Arul Arulmoli and Raj Varatharaj of EMI, who provided the p-y curves used in this investigation. Also acknowledged is the contribution of Neda Saeedy to the research reported in this paper.

\section{REFERENCES}

Arulmoli, K., and Martin, G. R., 2009. Seismic Soil-Structure Interaction Issues for PileSupported Piers and Wharves, ASCE Technical Council on Lifeline Earthquake Engineering (TCLEE2009), Oakland, CA.

Budek, A., Benzoni, G., and Priestley, M. J., 1994. In-ground plastic-hinges in column/pile shaft design, in Proceedings, 3rd Annual Caltrans Seismic Research Workshop, California Department of Transportation, Division of Structures Sacramento, CA.

Budek, A. M., Priestley, M. J., and Benzoni, G., 2000. Inelastic seismic response of ridge drilledshaft RC pile/columns, Journal of Structural Engineering 126, 510-517.

California State Lands Commission (MOTEMS), 2010. Marine Oil Terminal Engineering and Maintenance Standards, 2010 Title 24, California Code of Regulations, Part 2, California Building Code, Chapter 31F (Marine Oil Terminals), Long Beach, CA.

Federal Highway Adminsitration (FHA), 1986. Seismic Design of Highway Bridge Foundations, Vol. II: Design Procedures and Guidelines, Report No. FHWA/RD-86/102, Turner-Fairback Highway Research Center, McLean, VA.

Goel, R. K., 2013. Evaluation of In-Ground Plastic-Hinge Length and Depth Recommendations for Piles in Marine Oil and LNG Terminals, Report No. CP/SEAM-2013/01, California Polytechnic State University, San Luis Obispo, CA, available at http://works.bepress.com/ rgoel/62/.

Goel, R., and Saeedy, N., 2012. Plastic-hinge length and depth for piles in marine and LNG Terminals including nonlinear soil, in 15th World Conference on Earthquake Engineering, Lisbon, Portugal.

Lai, C., 2009. Port of Long Beach Wharf Design Criteria, Handbook, Long Beach, CA. 
McKenna, F., and Fenves, G., 2001. The OpenSees Command Language Manual, Version 1.2, Pacific Earthquake Engineering Center, University of California, Berkeley (last accessed https://opensees.berkeley.edu).

Neuenhofer, A., and Filippou, F., 1997. Evaluation of nonlinear frame finite-element models, Journal of Structural Engineering 123, 958-966.

Priestley, M. J., Seible, F., and Calvi, G. M., 1996. Seismic Design and Retrofit of Bridges, John Wiley \& Sons, Inc., New York.

Saeedy, N., 2013. In-Ground Plastic Hinge Analysis for Piles Used in Marine Oil and LNG Terminals, M.S. Thesis, California Polytechnic State University, San Luis Obispo, CA.

(Received 18 July 2013; accepted 16 April 2014) 